\title{
Youth in 4-H Latino Initiative programs achieve similar outcomes to youth in 4-H community clubs
}

Results from a pilot study suggest that adaptations to strengthen the cultural relevance of 4- $\mathrm{H}$ programs increase the number of Latino youth while realizing similar youth development outcomes.

By Steven Worker, Maria Fábregas Janeiro and Kendra Lewis

\section{Abstract}

Until recently, California 4-H programs did not represent the ethnic diversity found in California's population of young people. To close the gap in representation — particularly with Latino youth — UC ANR began the 4-H Latino Initiative, an effort to pilot adapted programs that would target the engagement of Latino youth and families. In this paper, we explore and compare young people's program experience and youth development outcomes between 4-H community clubs and 4-H Latino Initiative programs. We employed comparative post-test survey methodology with two treatment groups (community clubs versus 4-H Latino Initiative programs). The findings provide encouraging evidence that young people experienced positive outcomes from participating in 4-H programs, inclusive of both 4-H community clubs and 4-H Latino Initiative programs. Additionally, we found that the program experience — including relationship building and youth engagement — were similar across community clubs and 4-H Latino Initiative programs.

A 4-H Latino Initiative summer day camp at James Monroe Elementary School in Santa Rosa. In addition to day camps, the Initiative implemented in-school and after-school clubs, and special interest and short-term programs.
- The U.S. population is now 327 million people, up from 76 million in 1902, when 4-H was founded (US Census Bureau 1901, 2018). By 2020, more than half of U.S. children will be from a race or ethnic group other than non-Hispanic white (Chappell 2015). In California, over $54 \%$ of the $\mathrm{K}-12$ student population identifies as Hispanic or Latino (Ed-Data 2018). However, until recently, California 4-H programs did not represent this population well. For example, in the 2014-2015 school year, California 4-H served 73,246 youth, with only 24,042 youth (33\%) identifying as Hispanic or Latino, a gap of more than 21 points.

\section{Adapted programming to engage Latino youth}

UC Agriculture and Natural Resources (UC ANR) is committed to reaching all segments of the state's population in order to contribute to an inclusive and 
equitable society. Starting in the early 2010s, UC ANR Cooperative Extension advisors responsible for academic leadership of the 4-H Youth Development Program began to explore how 4-H could better serve Latino youth. The research base supported this transformation; other Cooperative Extension academics argued that 4-H must "become a more nimble organization, addressing the complex needs of young people from diverse backgrounds and settings" (Borden et al. 2014).

In 2015, UC ANR invested resources for a pilot effort, the 4-H Latino Initiative, focused on adapting programming to become culturally relevant and responsive to Latino youth - that is, programming that recognized effects of discrimination and economic poverty, tapped assets unique to local Latino youth (such as experience navigating two cultures), engaged Latino families and communities, and encouraged positive ethnic identity (Erbstein and Fabionar 2014). While the 4-H Latino Initiative focused on Latino youth, the hope was that adapted programming would emerge to help UC ANR better serve all youth of color.

\section{The 4-H Latino Initiative}

The 4-H Latino Initiative was piloted in seven counties. Full-time bilingual 4-H staff were hired in each county to assess interests of the Latino community, market $4-\mathrm{H}$ to Latino families and communities and implement culturally responsive $4-\mathrm{H}$ programs. The $4-\mathrm{H} \mathrm{La}-$ tino Initiative permitted flexibility in program models, structure and curriculum, within existing 4-H delivery modes (i.e., pre-defined program categories consisting of community clubs, special interest programs, shortterm programs, day camps, after-school and in-school clubs, and school enrichment), adapted to be culturally responsive for Latino youth and families. One significant factor was identifying how to adapt programming to engage Latino youth, be inclusive and accessible, and that offered similar high-quality youth development achieved by $4-\mathrm{H}$ community clubs. While Cooperative Extension has used an array of 4-H delivery modes other than 4-H community clubs for decades, this paper reports on data from the second year of a 3-year initiative to adapt programming to become more culturally relevant for Latino youth.

Efforts to be culturally relevant and responsive were built on work from Gay (2010) and Ladson-Billings (2014). Culturally responsive programs involve building and sustaining the engagement of Latino youth and families, which require that staff have intercultural skills, rethink recruiting processes and approach communities with a holistic cultural perspective (Fábregas Janeiro and Bird 2018; Fábregas Janeiro and Horrillo 2017). The 4-H Latino Initiative program adaptations included employing bilingual and bicultural staff and bilingual volunteer leaders, recruiting local Latino teenage mentors, providing opportunities for family involvement, choosing locations likely to target engagement of Latino youth and families, and including relevant curriculum selected by youth and families.

By the end of the second year of the 4-H Latino Initiative, all seven counties demonstrated an increase in Latino youth involvement and an increase in the proportion of Latino 4-H youth. Over the first 2 years of the Initiative, the seven counties reached an additional 10,000 Latino youth.

\section{4-H community club legacy}

The 4-H community club delivery mode began with the origins of the 4-H program in 1902 (Howe 1911; Wessel and Wessel 1982). The community club model quickly became the prevalent program model, a legacy that continues to the present day. Community clubs have been shown to support youth leadership, community service and project-based learning (Forero et al. 2009). However, as scholars have pointed out, many youth programs that formed at the turn of the 20th century have primarily served youth from dominant social groups and been less successful serving marginalized youth, youth of color, or youth from non-dominant social groups (Russell and Van Campen 2011).

Although the community club delivery mode was explored initially, community clubs were not heavily utilized in the 4-H Latino Initiative. The 4-H Latino Initiative programming primarily targeted new communities with no awareness or investment in 4- $\mathrm{H}$, and thus, new bilingual $4-\mathrm{H}$ staff experienced difficulties recruiting adult volunteers for long-term volunteer commitments with heavy administrative overhead. Additionally, staff encountered challenges working with existing community clubs to make adaptations to better reach Latino youth (Worker et al. 2019). Instead of utilizing the community club delivery mode, 4-H staff in the seven counties implemented programming using other $4-\mathrm{H}$ delivery modules 
TABLE 1. 4-H Latino Initiative programs

\begin{tabular}{|c|c|c|c|c|c|c|}
\hline County & Delivery mode & $\begin{array}{l}\text { No. of } \\
\text { sessions }\end{array}$ & $\begin{array}{l}\text { Session } \\
\text { length }\end{array}$ & Age range & $\begin{array}{l}\text { Approx. no. of } \\
\text { participants }\end{array}$ & Direct delivery educator \\
\hline & & & hours & years & & \\
\hline Kern & Special interest* & 6 & 2.0 & $5-18$ & $\begin{array}{l}\text { Age 5-8: } 11 \\
\text { Age 9-18: } 17\end{array}$ & $\begin{array}{l}\text { UC Cooperative Extension (UCCE) staff, partner } \\
\text { organization staff, 4-H volunteers (teenagers), 4-H } \\
\text { volunteers (adults) }\end{array}$ \\
\hline Merced & Day campt & 12 & 2.0 & $14-18$ & Age 14-18: 18 & UCCE staff, 4-H volunteers (adults) \\
\hline Merced & Short-term* & 6 & 2.5 & $14-18$ & Age 14-18: 11 & UCCE staff, partner organization staff \\
\hline Monterey & $\begin{array}{l}\text { 4-H after-school } \\
\text { club }\end{array}$ & 18 & 3.0 & $5-10$ & $\begin{array}{l}\text { Age 5-8: } 10 \\
\text { Age 9-18: } 7\end{array}$ & Partner organization staff \\
\hline Orange & Special interest* & 10 & 2.0 & $\begin{array}{c}5-10 \\
14-18\end{array}$ & $\begin{array}{l}\text { Age 5-8: } 10 \\
\text { Age 9-18: } 15\end{array}$ & UCCE staff \\
\hline Riverside & Special interest* & 6 & 1.0 & $5-13$ & $\begin{array}{l}\text { Age 5-8: } 50 \\
\text { Age 9-18: } 20\end{array}$ & UCCE staff \\
\hline Santa Barbara & 4-H in-school club & 30 & 1.0 & $11-13$ & Age 5-8: 71 & UCCE staff \\
\hline Sonoma & $\begin{array}{l}\text { 4-H after-school } \\
\text { club }\end{array}$ & 30 & 2.0 & $\begin{array}{c}5-10 \\
14-18\end{array}$ & $\begin{array}{l}\text { Age 5-8: } 34 \\
\text { Age 9-18: } 39\end{array}$ & $\begin{array}{l}\text { UCCE staff, } 4-\mathrm{H} \text { volunteers (teenagers), } 4-\mathrm{H} \\
\text { volunteers (adults) }\end{array}$ \\
\hline
\end{tabular}

TABLE 2. Demographics of older youth (age 9 to 18)

\begin{tabular}{|c|c|c|}
\hline Demographic variable & $\begin{array}{l}\text { 4-H community } \\
\text { clubs } \\
(n=495)\end{array}$ & $\begin{array}{c}\text { 4-H Latino Initiative } \\
\text { programs } \\
(n=131)\end{array}$ \\
\hline & $\%$ & $\%$ \\
\hline \multicolumn{3}{|l|}{ Gender } \\
\hline Female & 64.6 & 45.5 \\
\hline Male & 35.4 & 54.5 \\
\hline \multicolumn{3}{|l|}{ Ethnicity } \\
\hline Non-Hispanic or Latino & 83.2 & 23.1 \\
\hline Hispanic or Latino & 16.8 & 76.9 \\
\hline \multicolumn{3}{|l|}{ Race } \\
\hline White & 82.7 & 65.1 \\
\hline Black or African-American & 0.4 & 20.6 \\
\hline Asian & 3.2 & 3.2 \\
\hline American Indian or Alaska Native & 2.8 & 3.2 \\
\hline Native Hawaiian or other Pacific Islander & 0.0 & 1.6 \\
\hline Multiple races & 6.3 & 6.3 \\
\hline Undetermined & 4.5 & 0.0 \\
\hline \multicolumn{3}{|l|}{ Residence } \\
\hline Farm & 20.6 & 3.2 \\
\hline Town (nonfarm, rural, population $<10,000$ ) & 20.2 & 4.8 \\
\hline Town or city (population $10,000-50,000$ ) & 23.0 & 42.7 \\
\hline Suburb of city (population > 50,000) & 25.5 & 8.1 \\
\hline \multirow[t]{2}{*}{ Central city (population > 50,000) } & 10.7 & 41.1 \\
\hline & Mean (SD) & Mean (SD) \\
\hline Age & $12.46(2.31)$ & $12.12(2.56)$ \\
\hline Years in 4-H & $4.25(2.63)$ & $1.73(0.82)$ \\
\hline
\end{tabular}

Note: Percentage is based on valid percent; that is, based on those who answered the question. (including day camps, special interest, short-term, inschool and after-school clubs).

\section{Surveys of youth in 4-H community clubs and 4-H Latino Initiative programs}

We sought to compare young people's outcomes and experience in $4-\mathrm{H}$ community clubs with young people's outcomes and experience in 4-H Latino Initiative programs to determine whether the $4-\mathrm{H}$ Latino Initiative programs offered similar experiences and outcomes to 4-H youth. We employed post-test survey methodology using the same measures with two treatment groups to compare their means (Rea and Parker 2005). Our hypothesis was that there would be no statistical differences in the means on all measures. California youth (aged 5 to 18) participated in either a $4-\mathrm{H}$ community club or 4-H Latino Initiative program during the 2017-2018 program year. Data was collected from youth as their respective programs neared conclusion. Table 1 summarizes eight 4 -H Latino Initiative programs included in this study (note: more than eight programs were implemented but youth surveys were only administered in these eight), and their core components. Community club youth, aged 9 to 18 , completed surveys online using the Online Record Book (ORB) (for an explanation of ORB, see Lewis and Worker 2016), Qualtrics, or paper and pencil. Younger youth, aged 5 to 8 , completed surveys at state events near the end of the program year. 4 -H Latino Initiative program youth, aged 5 to 18 , completed the surveys using paper and pencil near the end of their respective program. We used a convenience sampling method. Youth demographics are presented in tables 2 and 3. Ethnicity and residence information was not collected for youth aged 5 to 8 . Demographics for youth in the 
community club program were pulled from the $4 \mathrm{HOn}$ line enrollment system. Demographics for youth in $4-\mathrm{H}$ Latino Initiative programs were collected on the last page of their survey. Youth self-identified their race and ethnicity using the options in table 2 .

We employed two survey instruments, one for youth aged 9 to 18 and another for younger youth, aged 5 to 8 . Both survey instruments assessed youth development outcomes and program experience.

To assess program outcomes of older youth, aged 9 to 18 , we used the National 4-H Common Measures 2.0 universal measure, which assesses social, emotional, character and leadership skills necessary for academic or workplace success (Hawley n.d.). The measure consists of 23 items; 10 items assess personal mindset (social and emotional skills; e.g., character, growth mindset and decision-making), 10 items assess social skills (social and leadership skills; e.g., ability to communicate, value and respect for other cultures) and three items are negatively worded to encourage deeper processing and are not included in the analyses. All personal mindset and social skills items provide four-point response options, coded such that No $=1$, Not really $=2$, Usually $=3$ and Yes $=4$. The National 4-H Common Measures 2.0 universal measure scale Cronbach alpha reliability was reported as 0.84 (Hawley n.d.). In the current study, both the personal mindset and social skills scales showed excellent Cronbach alpha reliability in community clubs $(0.80$ and 0.78 , respectively) and in $4-\mathrm{H}$ Latino Initiative programs ( 0.80 and 0.83 , respectively).

The older youth's program experience was assessed using a measure with items developed by academic coordinators and Cooperative Extension specialists; the Thrive Foundation for Youth, YMCA and Camp Fire; and Zeldin et al. (2014). Four items assess relationship building (e.g., "I feel like I belong in 4-H" and "Adults in 4-H support me when I try something new") and 12 items assess youth engagement (e.g., "I think youth and adults learn a lot from working together in $4-\mathrm{H}$ ", "I have a say in planning the activities in 4-H" and "I think youth in $4-\mathrm{H}$ have opportunities to lead an activity"). Items provide five-point response options, coded as Strongly disagree $=1$ to Strongly agree $=5$, or Never $=1$ to Most of the time $=5$. Both the relationship build ing and youth engagement scales showed excellent reliability in community clubs ( 0.77 and 0.92 , respectively) and in 4 -H Latino Initiative programs (0.83 and 0.89 , respectively).

The survey for the younger youth, aged 5 to 8, consisted of 10 items developed by academic coordinators. Six items assess outcomes and four items measure program experience. All items are on a five-point scale. We adapted the Wong-Baker Faces pain rating scale (Wong and Baker 2000) so the saddest face matches to Disagree and the happiest face matches to Agree; the middle three faces do not have a written anchor.

To analyze the older youth survey, we first created scales that represent the mean score for each set of questions (i.e., personal mindset, social skills, relationship building, youth engagement). Difference in these mean scores and items was tested using independent samples $t$-tests. Significance level was set at $p<0.05$. Younger youth survey items were analyzed individually; no scales were created. Sample size for each analysis varied based on missing data; numbers $(n)$ are noted in the figures. Cohen's $d$ (Cohen 1988) effect sizes were calculated and are presented for significant effects; an effect size of 0.20 is small and 0.50 is medium.

\section{Outcomes and experience of older youth}

In terms of outcomes among the older youth (9 to 18), the means were higher for community clubs than for 4-H Latino Initiative programs on both scales. We calculated independent samples $t$-tests to compare the means. There was not a statistically significant difference between groups on personal mindset, but there was a statistically significant difference for social skills; $t(178)=2.48, p<0.05$, effect size $=0.26$; although the practical significance (effect size) was small (fig. 1).

In terms of program experience, the means were higher for community clubs than for 4-H Latino Initiative programs on relationship building, but were the same for youth engagement. An independent

TABLE 3. Demographics of younger youth (age 5 to 8 )

\begin{tabular}{l|c|c|}
$\begin{array}{l}\text { Demographic } \\
\text { variable }\end{array}$ & $\begin{array}{c}\text { 4-H community clubs } \\
(\boldsymbol{n}=149)\end{array}$ & $\begin{array}{c}\text { 4-H Latino Initiative } \\
\text { programs }(n=124)\end{array}$ \\
\hline Gender & $\%$ & $\%$ \\
\hline Female & 52.2 & 48.0 \\
\hline Male & 47.8 & 52.0 \\
\hline Age & Mean (SD) & Mean (SD) \\
\hline Years in $4-\mathrm{H}$ & $7.08(1.15)$ & $7.06(0.91)$ \\
\hline
\end{tabular}

Note: Percentage is based on valid percent; that is, based on those who answered the question.

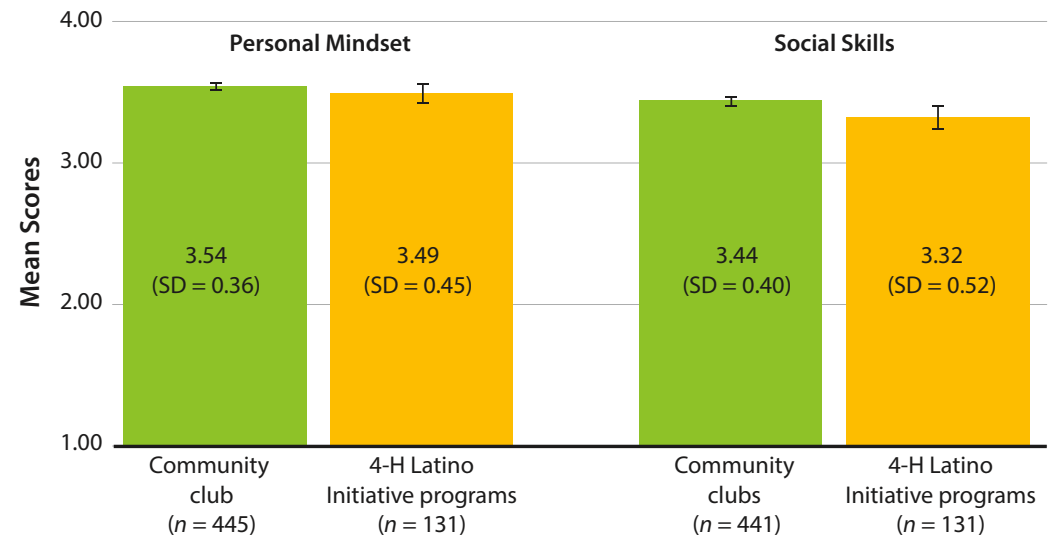

FIG. 1. Descriptive statistics for the personal mindset and social skills of the older youth (age 9 to 18), in community club and 4-H Latino Initiative programs. SD = standard deviation. Error bars are two times the standard error. 
samples $t$-test revealed a significant difference between groups on relationship building; $t(329)=2.06, p<0.05$, effect size $=0.22$. The practical significance between the means on relationship building was small (fig. 2).

\section{Outcomes and experience of younger youth}

In terms of outcomes among the younger youth (5 to 8 ), the means were higher for community clubs than for 4-H Latino Initiative on all six items. We calculated

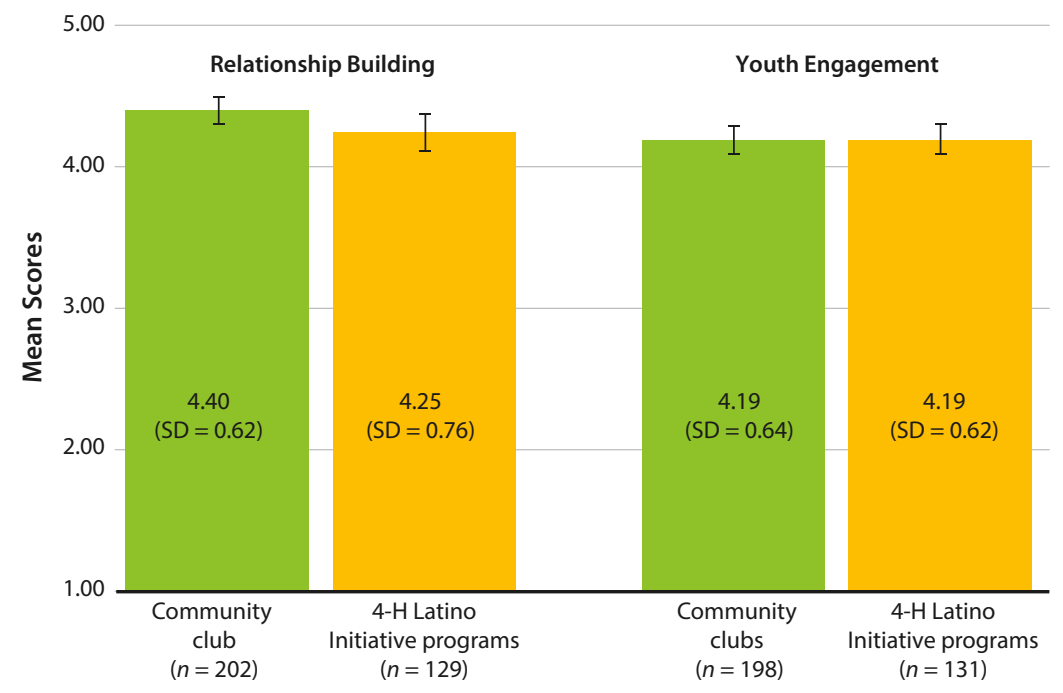

FIG. 2. Descriptive statistics for the relationship building and youth engagement of the older youth (age 9 to 18), in community club and 4-H Latino Initiative programs.

TABLE 4. Descriptive statistics for six outcome items on the younger youth survey (age 5 to 8$)$

\begin{tabular}{|l|c|c|}
\hline Item & $\begin{array}{c}\text { 4-H community club } \\
(\boldsymbol{n}=149)\end{array}$ & $\begin{array}{c}\text { 4-H Latino Initiative } \\
\text { programs }(\boldsymbol{n}=124)\end{array}$ \\
\cline { 2 - 3 } I can learn something even if it is hard & $4.52(0.81)$ & $4.32(1.05)$ \\
\hline I can set a goal & $4.49(0.88)$ & $4.34(1.02)$ \\
\hline I feel good about myself & $4.71(0.66)$ & $4.66(0.69)$ \\
\hline It is important to make good choices & $4.90(0.32)^{*}$ & $4.79(0.58)^{*}$ \\
\hline I can help someone if they need me & $4.68(0.71)$ & $4.60(0.89)$ \\
\hline $\begin{array}{l}\text { I have people in my life that care } \\
\text { about me }\end{array}$ & $4.89(0.48)$ & $4.76(0.77)$ \\
\hline
\end{tabular}

${ }^{*} t(182)=2.00, p<0.05$. Levene's test for equality of variances indicated variances were not equal; therefore we used results that adjust the standard error and degrees of freedom.

TABLE 5. Descriptive statistics for four program experience items on the younger youth survey (age 5 to 8 )

\begin{tabular}{|l|c|c|}
\hline Item & $\begin{array}{c}\text { 4-H community club } \\
(\boldsymbol{n}=149)\end{array}$ & $\begin{array}{c}\text { 4-H Latino Initiative } \\
\text { programs }(\boldsymbol{n}=124)\end{array}$ \\
\hline I made a friend in 4-H & $4.61(1.00)$ & $4.53(0.94)$ \\
\hline $\begin{array}{l}\text { The place where 4-H meets is safe } \\
\text { I think youth in 4-H are nice to each } \\
\text { other }\end{array}$ & $4.74(0.60)$ & $4.59(0.85)$ \\
\hline \begin{tabular}{l} 
I think adults in 4-H are nice to youth \\
\hline
\end{tabular} & $4.65(0.71)$ & $4.50(0.93)$ \\
\hline
\end{tabular}

independent samples $t$-tests between the means. The only statistically significant result was a difference between the means on the item "It is important to make good choices"; $t(182)=2.00, p<0.05$, effect size $=0.24$ (table 4).

In terms of program experience, the means were higher for community clubs than for 4-H Latino Initiative programs on all four items; however, independent samples $t$-tests revealed no significant differences on all items (table 5).

\section{Results similar in community clubs and 4-H Latino Initiative programs}

Our findings provided encouraging indications that young people experienced positive outcomes from participating in 4-H programs, including $4-\mathrm{H}$ community clubs and other programs adapted for the 4-H Latino Initiative. Additionally, the findings demonstrated that 4-H program experience - particularly relationship building and youth engagement - was similar across community clubs and 4-H Latino Initiative programs.

For older youth, findings showed significant differences for one outcome (social skills) and one program experience assessment (relationship building), although the practical significance (effect size) was small. Social aspects might be improved in the 4 -H Latino Initiative programs. These programs tended to be shorter in duration than the community club programs, and the time youth stayed in them was shorter (average $=1.7$ years) compared to the time youth stayed in community clubs (average $=4.3$ years) (table 2 ). Youth in $4-\mathrm{H}$ Latino Initiative programs may have needed more time in the program to build relationships with peers and adults; and future programming may want to increase the amount of time youth may participate; for example, by offering short-term programs multiple times so youth can continue participating.

The youth in this study differed not only in the delivery modes, but in their demographics. Youth from the community clubs tended to be from rural areas and identify as non-Hispanic white, while youth in $4-\mathrm{H}$ Latino Initiative programs tended to be from urban areas and identify as Hispanic white. These differences, paired with the mostly non-significant differences-or at least, small practical significance - in youth development outcomes and program experience, provide encouragement for 4-H professionals to continue developing and implementing delivery modes attractive to Latino youth. In other words, 4-H Latino Initiative programs may provide similar youth development outcomes and program experiences, regardless of ethnicity or residence.

The 4-H Latino Initiative programs were adapted specifically to improve UC ANR's reach with Latino youth. Our findings provided promising evidence that the adaptions we made to improve the cultural relevance of 4-H programs for Latino youth not only increased the numbers of Latino youth participants, 
